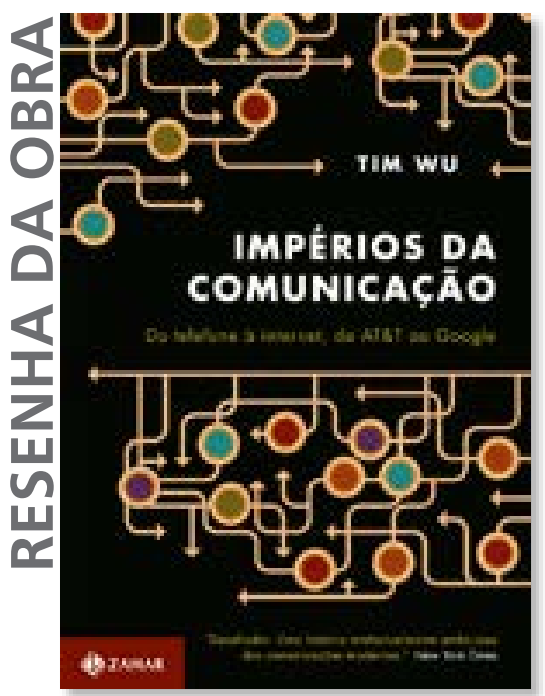

WU, Tim. Impérios da Comunicação: do telefone à internet, da AT\&T ao Google. Rio de Janeiro: Zahar, 2012, 432 p.

\title{
Tecnologias da informação e comunicação: inovação, liberdade e controle
}

Durante a guerra de ocupação do Iraque, apareceu um fenômeno de comunicação, os warblogs, que foi possível por causa do caráter libertário da internet. Os warblogs eram publicações independentes de profissionais de imprensa que não conseguiam fazer circular nos veículos para os quais trabalhavam muitas observações sobre o que estava se passando no país. Esses profissionais sofriam restrições das empresas às quais estavam vinculados e das forças de ocupação. Mas eles queriam dizer sua própria palavra e fazer circular o que viam. Publicações de suas matérias em blogs foi a saída encontrada. E os warblogs se converteram em um fenômeno de comunicação que trouxe para a cena pública muitas informações que as empresas de comunicação não tinham interesse em divulgar ou que órgãos de censura não deixavam circular.

Um dos mais famosos warblogs produzidos durante a guerra de ocupação do Iraque, o Baghdad Burning (CARYL, 2007) não foi obra de jornalista. Ele era publicado por uma jovem profissional da área de informática e oferecia uma visão do cotidiano no Iraque, a qual contrariava as versões oficiais do governo local e das forças de ocupação. Baghdad Burning driblava não somente os controles sobre conteúdo, mas também o controle sobre as linhas de comunicação no ciberespaço. Riverbend (nome fictício adotado pela blogueira), graças a seus conhecimentos de informática, conseguia colocar na rede, de forma 
independente, textos que contestavam as verdades oficiais. Baghdad Burning, em páginas bastante despojadas do ponto de vista gráfico, ainda pode ser encontrado na web em http://riverbendblog.blogspot.com.br/2003_08_01_archive.html.

Em 2003, Chris Boese, na época jornalista da rede CNN, resolveu apoiar colegas interessados em divulgar matérias sobre a guerra no Iraque não aceitas pelos veículos em que trabalhavam. Para tanto, ela desenvolveu ferramentas que facilitavam publicações na internet, além de dialogar com os interessados sobre as possibilidades que os blogs oferecem como plataformas de comunicação livre. Boese narra o apoio que deu a autores de warblogs em um texto que tem como referência o educador brasileiro Paulo Freire (BOESE, 2004). Como ela notou, as matérias produzidas por seus colegas tinham características de conscientização proposta pelo educador brasileiro:

À medida que [...] penetram na consciência pública, os blogs trazem consigo um exército interativo invisível, e sem precedentes, de participantes que podem estar vivenciando uma forma de consciência crítica (incômoda para o poder estabelecido). O objetivo é alcançar uma cultura cada vez mais democrática, assim como intencionava Paulo Freire (BOESE, 2004, p. 2).

Ao recorrer a Paulo Freire, Boese mostra que os warblogs publicados com seu apoio técnico foram exemplos de situações nas quais os autores puderam dizer suas próprias palavras. Esse modo de ver o papel das comunicações também era muito caro para outro educador, Don Lorenzo Milani, o criador da Escola de Barbiana (MARTí, 1977). Milani, em seu trabalho educacional, mostra que os jovens que fracassavam na escola pública italiana sofriam uma timidez resultante da incapacidade de se comunicar de modo articulado. Por essa razão, uma das marcas da proposta educacional de Milani é proporcionar aos estudantes ferramentas e domínio de linguagem que os tornem cidadãos capazes de entender e criticar informações, além da capacidade de produzir seu próprio discurso de maneira crítica e consciente.

Os warblogs são um exemplo muito claro de uso da internet para produzir um ambiente de comunicação libertário. Porém, é preciso perguntar se a livre circulação de informação continuará a existir na rede mundial de computadores. É essa a pergunta fundamental que levou Tim Wu a escrever The Master Switch: the rise and fall of information empires, traduzido para o português com o título Impérios da Comunicação: do telefone à internet, da AT\&T ao Google.

Wu examina origem e desenvolvimento das mais expressivas tecnologias da informação e comunicação desde a segunda metade do século 19 e nota que há um padrão ao qual ele dá o nome de Ciclo. As novas tecnologias, em sua origem, são instrumentos de livre expressão e dão lugar à esperança de que as comunicações se deem na direção de uma cidadania exercida sem barreiras 
de poderes econômicos e políticos. Com o tempo, as tecnologias de informação e comunicação acabam se tornando uma mercadoria dominada por monopólios que, para buscar mais poder e lucro, restringem as possibilidades dos meios, que passam a controlar, quase sempre, com a conivência de governos, que protegem as empresas e cerceiam iniciativas libertárias.

No momento, a internet ainda é um campo no qual práticas de livre expressão acontecem sem grandes restrições. E os entusiastas pela nova tecnologia acreditam que ela não terá o mesmo destino que as tecnologias que a precederam. Essa é uma esperança que, para o autor, precisa ser examinada a partir da história. $\mathrm{E}$, para tanto, convém verificar o que ocorreu com as tecnologias da comunicação desde o surgimento do telégrafo.

\section{Uma rede mundial de comunicação}

Wu reproduz um comentário que convém registrar aqui:

De todos os hobbies, a comunicação sem fio é a mais interessante. Ela oferece horizontes mais amplos, o mais aguçado fascínio, tanto por uma intensa competição com outros, próximos ou distantes, quanto por um estudo tranquilo e pura diversão nas horas mortas da noite, ao receber visitantes amigáveis de todo esse grande mundo (WU, 2012, p. 49).

Em uma primeira leitura, o texto parece sugerir usos da internet em um ambiente wireless. Mas não é disso que se trata. $\mathrm{O}$ autor fez tal registro a partir de considerações de Lee de Forest, um entusiasta pelo rádio, em 1920. Na época, com poucos recursos, era possível adquirir kits para montar um aparelho de transmissão e recepção radiofônica.

Nas origens, o rádio prometia participação em uma rede mundial de comunicação. Entusiastas pela nova tecnologia não apenas recebiam, mas também transmitiam mensagens de qualquer parte do mundo. A situação observada por volta de 1910 assemelha-se ao que hoje vemos na internet.

O fim da utopia quanto aos ideais libertários no rádio começou quando a organização das transmissões ganhou estrutura de uma rede cujo objetivo era financiá-las com a cada vez mais lucrativa venda de propaganda radiofônica. Em outras palavras, o rádio tornou-se um negócio lucrativo, envolvendo a produção de aparelhos receptores e redes nacionais de transmissão. Ficaram para trás os kits que os próprios interessados poderiam montar e o uso das ondas de rádio por amadores. Órgãos governamentais regulamentaram o uso das ondas radiofônicas, quase sempre favorecendo os monopólios, que controlavam a produção de aparelhos e a transmissão de programas. Amadores, como os descritos por Lee de Forest, e organizações da sociedade civil foram proibidos

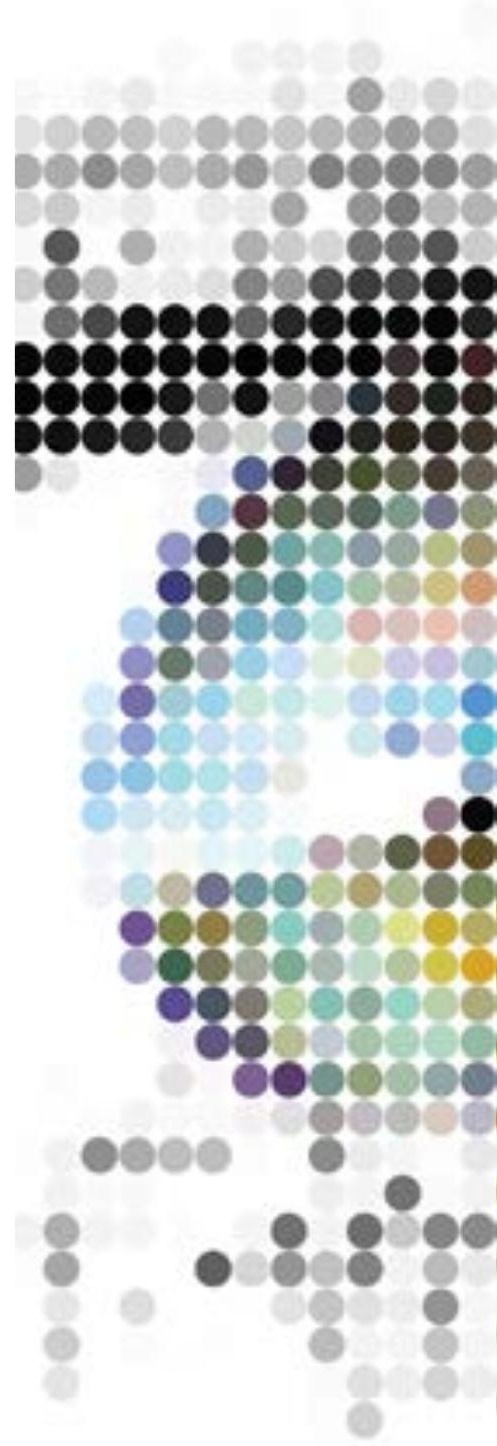




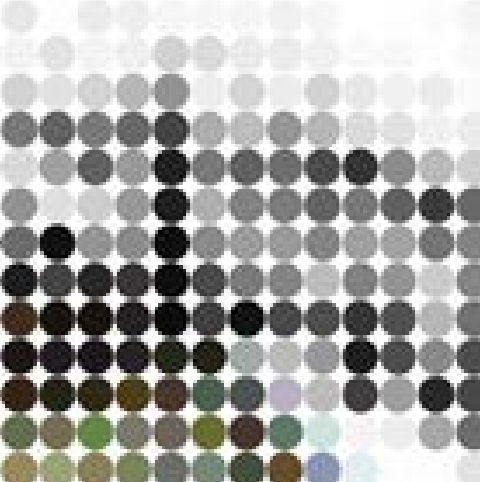 0000009 $8+8$ negócio, no qual a informação foi convertida em mercadoria. \\ O autor repara que, no Ciclo, há movimentos de inovação quando surge uma tecnologia disruptiva, que desafia a tecnologia hegemônica. Foi o que ocor- reu, por exemplo, com o telefone. A possibilidade de comunicação verbal a distância desalojou o telégrafo do lugar hegemônico que ocupava como tec- nologia de comunicação. Na história americana, segundo $\mathrm{Wu}$, a hegemonia alcançada pelo monopólio telefônico, o Sistema Bell, talvez seja o caso mais paradigmático do jogo que converte promessas de liberdade em domínio total dos espaços de comunicação e informação por umas poucas empresas. \\ Volto ao rádio. O monopólio na área, comandado pela National Broadcasting Company (NBC), além de eliminar o uso libertário da mídia, impediu que tecnologias inovadoras ocupassem o lugar de tecnologias já instaladas. O caso mais emblemático nesse sentido é o da Frequência Modulada (FM). Edwin Armstrong desenvolveu a tecnologia de transmissão FM para atender a um pedido da NBC, que queria melhorar a qualidade do som do rádio. Armstrong tinha um laboratório financiado pela NBC e já tinha desenvolvido várias tec- nologias que melhoraram consideravelmente as transmissões radiofônicas. No entanto, suas descobertas no campo da transmissão por FM contrariavam o interesse da empresa, cuja rede de emissoras tinha como base técnica a trans- missão por Modulação em Amplitude (AM). O inventor desenvolveu tecnolo- gias de transmissão por meio de $\mathrm{FM}$, que tinham maior alcance que as ondas em AM e, além disso, com qualidade superior de som. A qualidade e o longo alcance dos sinais de FM permitiam também a transmissão de texto e imagem, uma característica que nunca foi aproveitada, pois os interesses das empresas que controlavam a distribuição de informação, por cabos e por ondas de rá- dio, seriam ameaçados pela nova tecnologia.} 80000 $8:$ de usar livremente as ondas do rádio. Tudo foi transformado em um grande

A NBC impediu transmissões em FM, alegando que a tecnologia era experimental. Essa versão do monopólio do rádio foi adotada também pela agência governamental que regulava transmissões radiofônicas, a Federal Communications Commission (FCC).

Outra tecnologia de comunicação que teve seu desenvolvimento obstaculizado pelo monopólio do rádio foi a TV. Inventores independentes, nos Estados Unidos e na Inglaterra, desenvolveram tecnologias de transmissão de imagem em movimento na década de 1930. No entanto, essa tecnologia disruptiva, que poderia ameaçar as redes monopolistas radiofônicas, foi também classificada de experimental. A FCC favoreceu o monopólio do rádio mais uma vez e a TV, quando entrou no cenário regular de transmissões, foi descrita como imagem que acompanharia o som. Em outras palavras, a TV foi introduzida pela CBS como um veículo que apenas repetia, agora com imagens, os formatos já consagrados em transmissões radiofônicas. 


\section{Pedras pelo caminho}

O caso do rádio ilustra como o monopólio no campo das comunicações impede ou tenta impedir o desenvolvimento de novas tecnologias que possam mudar radicalmente o poder e a influência das grandes redes. Transmissões em FM e televisão foram apenas algumas das invenções que tiveram de vencer barreiras ou não poderiam ter seu potencial utilizado na direção de interesses sociais e exercício da cidadania. Convém resumir aqui algumas ocorrências na mesma direção em outros campos.

A TV, na medida em que as redes monopolistas a colocaram no ar, tinha problemas de transmissão de sinal para pequenas cidades distantes dos grandes centros. Revendedores de aparelhos de televisão colocaram em suas lojas imensas antenas para captar sinais das grandes redes e distribuíam as imagens, com ótima qualidade, por meio de cabos. Esse foi o modesto começo da TV a cabo. Os monopólios não criaram obstáculos para tal solução. A TV a cabo, em pequenas cidades, redistribuía seus programas e propaganda sem custo para as grandes emissoras. Mas tudo mudou de figura quando a TV a cabo começou a ser implantada nos grandes centros urbanos. Os monopólios, mais uma vez, recorreram às agências governamentais de controle e ao poder judiciário para impedir o ingresso da nova tecnologia, alegando direitos autorais sobre seus programas. Por outro lado, grupos da sociedade civil viam na TV a cabo possibilidades de uma televisão que desse margem à expressão de diversas vozes, democratizando tal mídia. O desenlace seguiu o roteiro do Ciclo. Legislação restritiva e ação de empreendedores deram origem, mais uma vez, a monopólios que dominam a transmissão de TV por cabo hoje em dia.

Outra batalha sucedeu no campo da telefonia. Quando apareceu, o telefone colocou em xeque a velha mídia de comunicação a distância, que dominava o cenário na segunda metade do século 19: o telégrafo. A empresa, que veio a ser conhecida como sistema Bell, instalou-se e começou a crescer. Converteu-se em monopólio nos grandes centros, mas sem interesse por linhas locais em pequenas cidades e áreas rurais. Iniciativas locais resultaram no surgimento de pequenas empresas de telefonia, algumas delas servindo-se, inclusive, do arame farpado das cercas de fazendas como linhas de transmissão. Mas, com o tempo, essas empresas independentes foram vistas como ameaças ao sistema Bell, o qual, por meio de compras, chantagens e até mesmo sabotagem, inviabilizou a existência de companhias telefônicas independentes.

O monopólio da Bell abarcava tudo: linhas de transmissão, aparelhos de recepção, serviços de longa distância e todos os equipamentos vinculados à telefonia. O sistema não aceitava qualquer inovação produzida fora dos muros da companhia. Isso deu margem a um caso que tem tintas folclóricas, o produto Hush-A-Phone, um invento que permitia falar ao telefone sem que pessoas na proximidade ouvissem o que estava sendo dito. Era um equipamento simples 
de isolamento acústico que, acoplado a um aparelho telefônico, preservava a intimidade de quem falava. A American Telegraph and Telephone (AT\&T), companhia que abarcava todo o sistema Bell, acusou a inovação como algo que interferia no funcionamento eficiente de seus aparelhos e poderia até causar acidentes a funcionários de manutenção do sistema Bell. Essas acusações não tinham qualquer base científica, mas foram aceitas pela FCC e o Hush-A-Phone foi proibido. A AT\&T julgava que ele era mau exemplo, pois outros complementos poderiam surgir, mudando o padrão estabelecido pelo monopólio e tido pelo governo como garantia de serviço de boa qualidade.

\section{A saga do cinema}

Wu historia o surgimento e desenvolvimento das mídias de comunicação modernas, mostrando como todas elas seguem o padrão do Ciclo. É interessante registrar algumas de suas observações sobre o cinema. Este, no começo do século 20, era inteiramente dominado por um truste que controlava o uso dos equipamentos de filmagem e projeção. O truste do cinema estabeleceu um padrão de produção que dava pouca margem à criatividade. Os produtores não podiam realizar filmes muito longos, nem investir em películas estreladas por artistas famosos. Alguns donos de salas de projeção queriam romper com tal determinação, importando filmes da Europa ou até produzindo longas-metragens com seus próprios recursos. As leis de patente favoreciam o truste de cinema.

Os proprietários insatisfeitos de salas de projeção se rebelaram contra o truste e contra a lei, começando a produzir seus próprios filmes na Costa Oeste. Surgiram, assim, os estúdios de Hollywood. No movimento típico do Ciclo, os novos produtores de cinema derrubaram o truste e, por sua vez, constituíram grandes oligopólios que dominaram verticalmente toda a cadeia da indústria cinematográfica, da produção à distribuição e projeção. Para tanto, acabaram com as companhias independentes de exibição, utilizando métodos que foram da pressão financeira a incêndios de casas de exibição cujos donos se recusavam a vender seus teatros aos oligopólios liderados pela Paramount.

O autor mostra uma face dos oligopólios do cinema que merece registro: a Legião da Decência. Os produtores que derrubaram o truste fizeram cinema com muita liberdade. Isso não agradou aos que julgavam que o cinema deveria seguir caminhos bastante restritivos de moralidade e que iniciaram, assim, um movimento que teve milhões de adeptos entre os crentes de igrejas cristãs. A indústria cinematográfica fez um acordo com a Liga da Decência e esta passou a examinar todos os roteiros antes das filmagens, realizando cortes ou simplesmente vetando toda obra. A situação, iniciada no fim dos anos de 1920, durou mais de três décadas. E todo o cinema da época seguiu estritamente um código de moralidade que nenhuma liberdade permitia à criação de au- 
tores que quisessem mostrar situações que contrariavam o fundamentalismo ético dos grupos religiosos. Wu observa que a ação da Liga da Decência foi possível porque os cinco oligopólios do cinema em Hollywood concentravam toda a produção e distribuição, não havendo qualquer espaço para criações independentes. Esse é mais um traço que a concentração do poder em poucas empresas na área de comunicação pode favorecer. Incidentalmente, cabe observar que grandes empresas da internet tendem a adotar medidas moralistas, impedindo algumas vezes a livre manifestação do pensamento.

Wu não aborda a mídia impressa. Mas sua narrativa sobre as atividades da Liga da Decência no cinema lembra um fenômeno cada vez mais preocupante no campo da produção de livros didáticos: lobbies para que textos produzidos para atividades de ensino não contenham qualquer conteúdo que desagrade grupos que exercem grande vigilância sobre as editoras. Como observa Diane Ravitch, em um estudo clássico sobre a questão, os livros didáticos são muito policiados atualmente, com prejuízos evidentes para a liberdade no campo da educação (RAVITCH, 2003).

\section{A internet seguirá o mesmo caminho que as outras mídias?}

A tecnologia disruptiva mais recente no campo da informação e comunicação é a internet. Na sua origem, ela foi planejada como um espaço de grande liberdade. Ameaças a uma internet livre já houve, mas usuários combativos têm até agora conseguido que se preserve o que é chamado de neutralidade da rede. Wu parece sugerir que essa liberdade não será duradoura. Já há indícios de que as grandes empresas no campo das tecnologias digitais caminham na direção do controle e de restrições de uso da mídia.

Ao analisar a história da Apple, o autor nota que a empresa abandonou o ideal de arquitetura aberta que caracterizava suas primeiras máquinas. Atualmente, os equipamentos da empresa são fechados e restringem acesso aos conteúdos da rede que não sejam produzidos ou gerenciados pelos grupos de mídia com os quais a Apple se associa. Investimentos em beleza e eficiência dos charmosos produtos da empresa acentuam facilidade de uso (conveniência), mas sacrificam a abertura que caracterizou a mais importante criação de Steve Wozniak, o Apple II.

Outra indicação de que a internet poderá ingressar na segunda fase do Ciclo é a de que as empresas que dominam as linhas de comunicação continuam a pressionar governos para que permitam que veiculem exclusivamente conteúdos por elas produzidos. Se isso for efetivado, a internet deixará de ser um 
espaço de liberdade no qual os usuários podem fazer suas escolhas e, se o desejarem ser autores, dizer suas próprias palavras.

$\mathrm{Na}$ internet, o Ciclo ainda não chegou inteiramente à fase de controle característica dos monopólios e oligopólios que dominam ou dominaram as demais tecnologias da informação e comunicação. Resta ainda uma esperança de que a resistência dos usuários impeça que tal desenlace ocorra.

\section{Comunicação e educação}

A obra de Tim Wu coloca questões que educadores precisam considerar. Quando os meios de comunicação são dominados por monopólios, a informação se converte em mercadoria. E os consumidores de tal mercadoria podem não ter consciência do que está sobrevindo. Não serão senhores de suas próprias palavras. Talvez, como fez Chris Boese, valha recorrer a Paulo Freire para encontrar caminhos de liberdade para superar barreiras que a segunda fase do Ciclo cria para uso consciente e crítico de tecnologias da informação e comunicação.

\section{Referências}

BOESE, Christine.The spirit of Paulo Freire in Blogland: struggling for a knowledge-log revolution. Minnesota: University of Minnesota, 2004. Disponível em: <http://hdl.handle.net/11299/172834>. Acesso em: 6 jul. 2016.

CARYL, Christian. What about the Iraqis. New York Review of Books, Jan. 11, 2007. MARTÍ, Miguel. El maestro de Barbiana. Barcelona: Nova Terra, 1977.

RAVITCH, Diane. The language police: how pressure groups restrict what students learn. New York: Alfred A. Knoff, 2003.

WU, Tim. Impérios da Comunicação: do telefone à internet, da AT\&T ao Google. Rio de Janeiro: Zahar, 2012, 432 p.

\section{Jarbas Novelino Barato}

Professor. Doutor em Educação pela Universidade Estadual de Campinas (Unicamp). Mestre em Tecnologia Educacional pela San Diego State University (SDSU). E-mail: jarbas.barato@gmail.com 